\title{
OS EFEITOS DA DECISÃO DE REMOÇÃO DE CONTEÚDO DIGITAL ELEITORAL APÓS AS ELEIÇÕES
}

\author{
The Effects of the Decision to Remove Electoral Digital Content after the Elections
}

Alinne Lopes Gomes

Diogo Rais

\author{
Frederico W. P. Pol Fernandes \\ Patrícia Helena Marta Martins
}

Resumo: Este artigo tem por objetivo apresentar as atividades normativa e jurisdicional do Tribunal Superior Eleitoral (TSE) diante do período de eficácia das ordens judiciais que determinem a remoção de conteúdo digital durante as eleições. Além disso, aborda a atuação da Justiça Eleitoral no julgamento dos conflitos sobre a regularidade da propaganda eleitoral na internet, em especial, diante do art. $33 \int 6^{\circ}$ da Resolução/TSE nº 23.551, de 2017 que foi o primeiro a regulamentar sobre a perda da eficácia das ordens judiciais que determinam a remoção de conteúdo digital após as eleições. Busca também, compreender os avanços e as alterações nos limites da sistematização legal acerca da remoção de conteúdo digital definida pelo TSE na Resolução 23.610/2019, vigente para as eleições de 2020, e a aplicação de tais diretrizes nas resoluções futuras.

Palavras-chave: Resolução. Remoção de conteúdo. TSE. Julgados. Eleições.

\begin{abstract}
This article aims to demonstrate the Superior Electoral Court normative and jurisdictional functions regarding digital content removal judicial decisions effectiveness period during the election season. The article also addresses the Electoral Justice's role in judging conflicts over the regularity of electoral advertising on the Internet, regarding especially the applicability of art. 33 $\int 6^{\circ}$ of Resolution/TSE 23551/2017, which states that illegal electoral advertising removal decisions, issued during elections, should be suspended after the electoral season. Finally, this study seeks to understand the development and changes in the legal systematization limits, considering the new digital content removal ruling brought by Resolution/TSE 23610/2019 and its applicability on future resolutions.
\end{abstract}

Keywords: Resolutions. Content removal. TSE. Precedents. Elections.

Artigo recebido em 16 set. 2019 e aprovado em 29 set. 2020. 


\section{Introdução}

O presente artigo tem como objetivo trazer ao leitor uma ideia concreta de como se organiza a função fiscalizatória da Justiça Eleitoral em relação ao combate das propagandas eleitorais irregulares durante o período eleitoral no âmbito virtual, considerando a sua larga propagação, estritamente na web, durante os últimos anos.

Será demonstrado que, além da atividade fiscalizatória atribuída à Justiça Eleitoral, sua função normativa também traz relevante papel para o combate às referidas propagandas eleitorais irregulares, na medida em que legitima diversos métodos utilizados pela atividade jurisdicional da justiça especializada, como a determinação de remoção de conteúdos considerados ilícitos, no intuito de que o debate democrático político não seja afetado, principalmente, pela desinformação.

A esse respeito, o artigo busca expor em detalhes a aplicabilidade do art. $33 \int 6^{\circ}$ da Resolução n. 23.551/2017, que foi o primeiro a regulamentar, especificamente, questões envolvendo os limites da eficácia das decisões judiciais que tratam sobre a retirada de circulação de propagandas eleitorais e condutas ilícitas em campanhas eleitorais para a disputa presidencial do ano de 2018 na internet; a importância de sua manutenção nas disputas eleitorais futuras, garantindo ao eleitorado proteção a direitos fundamentais relevantes como a liberdade de expressão, acesso à informação e vedação à censura e, ainda, às alterações trazidas pelo art. 38 , $\int 7^{\circ} \mathrm{da}$ Resolução n. 23.610/2019, que trata sobre a mesma temática na disputa eleitoral do ano de 2020.

O disposto no art. $33 \int 6^{\circ}$ da Resolução n. 23.551/2017, sobre a perda de eficácia das ordens judiciais de remoção de conteúdo após o encerramento do pleito, foi ratificado pelo Tribunal Superior Eleitoral e aplicado pelos demais Tribunais Regionais Eleitorais durante as eleições do ano de 2018.

Tomando conhecimento da edição especial da Revista Resenha Eleitoral deste Tribunal Regional Eleitoral do Estado de Santa Catarina, diretamente ligada à Sistematização das Normas Eleitorais, coordenada pelo Grupo de Trabalho do TSE, o presente artigo traz amplo substrato sobre os impactos da aplicabilidade do referido art. $33 \int 6^{\circ}$ da Resolução n. 23.551/2017 durante as eleições de 2018, de que forma isso afetou os 
debates legislativos para a eleição do ano de 2020 e, principalmente, a estruturação de tal diretriz na Resolução n. 23.610/2019 do TSE.

Denota-se que a aplicabilidade do art. $33 \int 6^{\circ}$ da Resolução n. 23.551/2017, assim como o art. 38, \ 7º da Resolução n. 23.610/2019, é de suma importância para a instrumentalização do combate às propagandas eleitorais irregulares veiculadas na web, diante da possibilidade de que os conteúdos veiculados nessa modalidade, principalmente em redes sociais, que venham a ser removidos em cumprimento à determinada ordem judicial proferida pela Justiça Eleitoral, sejam reestabelecidos após o encerramento do pleito caso não se verifique quaisquer ilegalidades que transcenda o ilícito eleitoral.

Não há dúvida de que a utilização da Internet em larga escala pelos candidatos na divulgação de suas campanhas representa um benefício que apenas foi possível de ser alcançado a partir das novas tecnologias desenvolvidas nos últimos anos, como as redes sociais, por exemplo.

Com base nas conclusões apresentadas no presente artigo, poderá ser realizada uma análise específica sobre a aplicabilidade do art. 33 \ $6^{\circ}$ da Resolução n. 23.551/2017, a relevância de sua manutenção para o debate democrático político no âmbito virtual durante os próximos períodos eleitorais e os aperfeiçoamentos trazidos pelo TSE em 2019 a esse respeito, refletidos no art. 38 \ 7ํ da Resolução n. 23.610/2019.

A pesquisa ora apresentada foi elaborada, principalmente, com base em análise jurisprudencial de julgados proferidos pelo Tribunal Superior Eleitoral referentes à remoção de conteúdos e a eficácia do artigo $33 \int 6^{\circ}$ da Resolução n. 23.551/2017. Foram utilizados, ainda, como fonte primária, artigos científicos e, de forma secundária, doutrinas de direito eleitoral, bem como as sugestões do grupo de Sistematização das Normas Eleitorais (SNE), alterações concretizadas pela Resolução n. 23.610/2019 e os recentes debates acerca da responsabilização das plataformas e a remoção de conteúdo para as eleições de 2020.

A pesquisa realizada foi de natureza qualitativa, focando na exposição e compreensão aprofundada de conceitos e ideias, referentes à aplicabilidade do artigo 33 \ $0^{\circ}$ da Resolução n. 23.551/2017 na disputa eleitoral do ano de 2018 e das alterações trazidas pela Resolução n. 23.610/2019, usando como fundamento, principalmente, conclusões extraídas das análises documentais de precedentes jurisprudenciais e dados disponíveis nos 
Tribunais Regionais Eleitorais. Os resultados foram apresentados de forma a compreender o posicionamento atual do TSE sobre o assunto

O objetivo principal do artigo foi construir uma perspectiva para as futuras eleições, ressaltando a importância da manutenção do racional trazido pelos respectivos artigos legais em referência, e os limites de eficácia das decisões proferidas pela Justiça Eleitoral quando se trata de remoção de conteúdo digital.

\section{A modernização das tecnologias e o processo eleitoral}

O Direito Eleitoral é um ramo do direito público, instrumentalizado por meio de uma legislação específica e especializada, como o Código Eleitoral (Lei 4.737/65) e a Lei das Eleições (Lei 9.504/97) ${ }^{1}$, que busca regular o exercício da soberania popular principalmente em relação ao sufrágio, com o intuito de garantir a efetiva democracia, adequada corretamente entre a vontade do povo e a atividade governamental.

Dentre as competências desempenhadas pela Justiça Eleitoral, destaca-se a sua função normativa ${ }^{2}$, caracterizada pela edição de resoluções expedidas pelo Tribunal Superior Eleitoral.

As resoluções devem ser expedidas até o dia 5 (cinco) de março do ano de cada eleição, conforme previsões do art. 105 da Lei 9.504/97³ , e têm como objetivo principal regulamentar o processo eleitoral, conferindo-lhe eficácia e garantindo que seu andamento esteja de acordo com o momento vivido pelo país.

Para além do poder normativo, a Justiça Eleitoral também atua julgando conflitos eleitorais, dentre eles, as questões sobre propaganda eleitoral irregular, como ocorre tanto com as propagandas eleitorais antecipadas

\footnotetext{
${ }^{1}$ Outros diplomas também regulamentam o Direito Eleitoral, como a Constituição Federal de 1988; a Lei Complementar n⿳o 64, de 18 de maio de 1990 (Lei de Inelegibilidade); a Lei no 9.096, de 19 de setembro de 1995 (Lei dos Partidos Políticos); e até o Código de Processo Civil (Lei 13.105/15) de forma subsidiária.

${ }^{2}$ Além da função normativa, a Justiça Eleitoral desenvolve funções consultiva, administrativa e jurisdicional.

${ }^{3}$ Art. 105. Até o dia 5 de março do ano da eleição, o Tribunal Superior Eleitoral, atendendo ao caráter regulamentar e sem restringir direitos ou estabelecer sanções distintas das previstas nessa lei, poderá expedir todas as instruções necessárias para sua fiel execução, ouvidos, previamente, em audiência pública, os delegados ou representantes dos partidos políticos.
} 
(veiculadas antes do início do período eleitoral) ${ }^{4}$, quanto com as propagandas eleitorais negativas ${ }^{5}$.

Alguns conflitos jurisdicionais sobre propaganda eleitoral antes dos avanços do cenário digital eram, de certa forma, menos desafiadores. Em regra, a mensagem era transmitida para os eleitores via televisão, rádio ou imprensa escrita, refletindo um modelo de comunicação "de um para muitos", ou seja, um emissor e inúmeros receptores. Nesses veículos, o objeto de controle era reduzido porque a quantidade de emissores também era limitada.

Atualmente, a atividade de atuação da Justiça Eleitoral tomou uma nova dimensão na medida em que as propagandas eleitorais estão migrando dos veículos exclusivos de imprensa, como rádios e televisão, para a web.

$\mathrm{Na}$ internet, os usuários produzem conteúdo e/ou repassam informações de maneira mais dinâmica, quer via blogs, quer via aplicativos de mensagens instantâneas e redes sociais.

Diversamente dos veículos tradicionais de comunicação, na internet, aquele que emite a informação é também aquele que a recebe, gerando um modelo de comunicação baseado na interação de "muitos para muitos". Ou seja, agora, os próprios candidatos podem, a qualquer instante durante o período eleitoral, veicular na rede, notícias e informações a seu respeito e a respeito de seus adversários, atingindo um número imenso de eleitores que estejam conectados.

Segundo o IBGE 6 , o Brasil conta com aproximadamente 126,3 milhões de usuários conectados à internet. Nesse sentido, outra relevante fonte sobre a utilização da Internet em escala global, a "Digital Global Overview" , discorre que os usuários conectados à rede no Brasil permanecem

${ }^{4}$ A propaganda eleitoral somente é permitida após o dia 15 de agosto do ano da eleição.

5 “A propaganda eleitoral pode ser de dois tipos: positiva e negativa. A propaganda positiva é aquela que exalta qualidades do candidato ou de suas propostas, currículos e biografia política. A propaganda negativa, por sua vez, é aquela que busca exaltar os pontos depreciativos de determinado candidato, podendo referir-se às características pessoais ou políticas". [BORBA, Felipe. Propaganda negativa nas eleições presidenciais brasileiras. In: Opinião Pública, Campinas, v. 21, n 2, agosto, 2015. p. 280].

${ }^{6}$ Disponível em: < https://agenciadenoticias.ibge.gov.br/agencia-sala-de-imprensa/2013-agencia-de-noticias/releases/23445-pnad-continua-tic-2017-internet-chega-a-tres-em-cada-quatro-domicilios-do-pais>. Acesso em: 03 ago. 2019.

7 "Digital in 2018 Global Overview". Disponível em: <https://digitalreport.wearesocial. com/>. Acesso em: 03 ago. 2019. 
cerca de nove horas e 14 minutos diários conectados, principalmente em redes sociais (aproximadamente três horas e 23minutos).

Contando com isso, não é à toa que o conteúdo on-line vem desempenhando relevante influência na tomada de decisão do eleitor. Segundo o Ibope ${ }^{8}$ :

(...) as mídias sociais têm algum grau de influência para mais da metade dos eleitores brasileiros (56\%) na escolha de seus candidatos e, para nada menos que $34 \%$ dos eleitores, os meios digitais têm muita influência 9 .

Diante dessa nova realidade, o Tribunal Superior Eleitoral já se manifestou sobre a distinção entre a internet e os veículos de comunicação tradicionais:

(...) Isso porque, ao contrário dos demais meios de comunicação social, a transmissão de dados pela internet não se exaure no momento em que se realiza. Nos rádios e nas televisões, uma vez divulgada a notícia, o espaço de divulgação passa a ser ocupado pela programação que se segue.

A internet, neste aspecto, é estática. A manutenção da informação em sítio da rede permite o acesso contínuo, a qualquer hora, de qualquer lugar do mundo.

A internet se diferencia dos veículos de comunicação impressos por não sofrer as consequências dos desgastes naturais que esmaecem e tornam esquecidos os jornais e as revistas. E mais: os mecanismos existentes permitem constante interação e atualização do conteúdo e não exigem enormes espaços físicos dos usuários para a conservação de material impresso. ${ }^{10}(\ldots)$

\footnotetext{
${ }^{8}$ IBOPE Inteligência. Redes sociais e mídias tradicionais são as fontes de informação com mais influência na escolha do presidente em 2018. Disponível em: <http://www.ibopeinteligencia.com/noticias-e-pesquisas/redes-sociais-e-midias-tradicionais-sao-as-fontes-de-informacao-com-mais-influencia-na-escolha-do-presidente-em-2018/>. Acesso em: 23 jul. 2019.

${ }^{9}$ Direito Digital Eleitoral / Diogo Rais, coordenador; São Paulo: Thomson Reuters Brasil, 2018. p. 19.

10 TSE, Agravo Regimental em Ação Cautelar 138443/DF, Rel. Min. Henrique Neves da Silva, j. em 29.06.2010, DJe 17.08.2010.
} 
Nesse novo cenário social, a Justiça Eleitoral se adaptou e definiu novas regras para cessar o fluxo de propagandas eleitorais irregulares veiculadas pela internet ${ }^{11}$. Como resultado, hoje a Lei das Eleições conta com um capítulo específico (Propaganda na Internet - art. 57-A ao 57-J) para regulamentar as propagandas virtuais.

Na mesma esteira, o TSE editou a Resolução n. 23.551/2017 _ publicada para as eleições de 2018 -, que, pela primeira vez, trouxe disposições específicas para o tratamento da "Remoção de Conteúdo da Internet".

Contudo, é essencial que a necessidade de cessar propagandas eleitorais irregulares durante o período eleitoral por meio da remoção específica desses conteúdos não sobreponha à garantia da liberdade de expressão e ao acesso à informação dos candidatos e eleitores, que são pilares do sistema democrático vigente no País.

\section{A perda da eficácia das decisões que determinam a remoção de conteúdo eleitoral digital em face da modernização da propaganda eleitoral: art. $33 \int 6^{\circ}$ da Resolução n. 23.551/2017}

Muitos julgados entendem que após o encerramento do período eleitoral, as representações eleitorais ajuizadas com o objetivo de cessar eventual propagação de propagandas eleitorais antecipadas ou negativas perderiam o objeto $^{12}$.

A perda do objeto das representações eleitorais garante que o poder fiscalizatório da Justiça Eleitoral não ultrapasse o limite do pleito, inclusive em atenção ao princípio da menor interferência possível no debate democrático. Afinal, é plenamente possível que certa ilicitude em determinado conteúdo seja caracterizada como ilícita exclusivamente no âmbito do período eleitoral.

Embora haja julgados nesse sentido, há também algumas decisões que entendem pela manutenção da indisponibilidade do conteúdo eleitoral irregular, mesmo após o encerramento do pleito.

\footnotetext{
${ }^{11}$ Alterações significantes ocorreram em 2009 (Lei 12.034/2009) e 2017 (13.488/2017).

${ }^{12}$ Nesse sentido: (TSE - AI: 06028412020186130000 Belo Horizonte/MG, Relator: Min. Luiz Edson Fachin, Data de Julgamento: 14/02/2019. Data de Publicação: DJE - Diário de Justiça Eletrônico - 18/02/2019).
} 
O questionamento é pertinente: com a perda do objeto da representação eleitoral decorrente do encerramento do pleito, os conteúdos removidos em cumprimento à determinada ordem judicial eleitoral (no geral, propagandas eleitorais negativas), devem ser reativados pelas mídias digitais após o contexto eleitoral?

A Resolução n. 23.551/2017, editada pelo Tribunal Superior Eleitoral para regulamentar a disputa eleitoral de 2018, detalhou a matéria e determinou a perda dos efeitos da decisão de tal natureza logo após o encerramento do período eleitoral.

Art. $33 \int 6^{\circ}$. Findo o período eleitoral, as ordens judiciais de remoção de conteúdo da internet deixarão de produzir efeitos, cabendo à parte interessada requerer a remoção do conteúdo por meio de ação judicial autônoma perante a Justiça Comum.

Em outras palavras, a Justiça Eleitoral, por meio de autocontenção, limitou o alcance de suas decisões ao período eleitoral.

Entretanto, na atuação jurisdicional, em especial durante os debates travados em duas representações eleitorais ajuizadas durante o período eleitoral para disputa presidencial do ano de 2018, o TSE retomou a questão.

A representação eleitoral de $\mathrm{n}^{\circ}$ 0601765-21.2018.6.00.0000 ${ }^{13}$, ajuizada pelo então candidato à presidência da República, Fernando Haddad, e pelo ex-presidente Lula, junto à Coligação "O povo feliz de novo", em face do Facebook Brasil, Twitter e Google, tratou de potencial necessidade de envolvimento da Justiça Eleitoral para que fossem removidos conteúdos veiculados nas plataformas das mídias sociais por, supostamente, configurarem propaganda eleitoral negativa.

Em análise sumária dos fatos trazidos pelos representantes, a Corte entendeu que alguns, dentre os conteúdos demandados, configuravam propaganda eleitoral negativa, por envolverem informações inverídicas. Em razão disso, a Justiça Eleitoral determinou, em antecipação de tutela, a retirada de circulação de tais conteúdos.

Nessas circunstâncias, a decisão liminar determinou que as empresas Facebook e Google retirassem do ar, em 24 horas, os conteúdos indicados

13 (TSE - Rp: 06017652120186000000 Brasília/DF, Relator: Min. Sérgio Silveira Banhos. Data de Julgamento: 19/10/2018. Data de Publicação: PSESS - Mural eletrônico - 20/10/2018). 
pela Corte. E, em cumprimento à tal decisão, as empresas comprovaram, tempestivamente, a indisponibilização do material demandado.

Ao final, foi proferida a sentença da representação eleitoral, em que restou consignada a prejudicialidade do pedido de direito de resposta em função do fim das eleições e a improcedência do pedido de aplicação de multa aos usuários dada a inexistência de anonimato ${ }^{14}$, afastando-se expressamente os efeitos da medida liminar anteriormente deferida, em atenção ao art. $33 \int 6^{\circ}$ da Resolução n. 23.551/2017.

Em desacordo com o resultado, os representantes recorreram da decisão, buscando a continuidade dos efeitos da liminar, sob o argumento de que os danos causados à figura política permaneceriam mesmo após o término do pleito. Ainda, os recorrentes alegaram no apelo que, como já teria sido reconhecido o potencial lesivo do conteúdo, a revogação de decisão da Justiça Eleitoral caracterizaria complacência com a conduta ilegal.

Durante o julgamento do recurso, o Ministro Alexandre de Moraes expressou divergência irreconciliável com o artigo 33 parágrafo $6^{\circ} \mathrm{da}$ Resolução n. 23.551 do TSE, adotando entendimento de que a proteção da honra e a decisão devidamente fundamentada da Justiça Eleitoral devem garantir a segurança jurídica dos representantes, mesmo depois de encerrado o período eleitoral. Segundo o Ministro, a honra permanece sendo ferida após as eleições e, com a manifestação da Justiça Eleitoral acerca da ilicitu-

\footnotetext{
14 “Assim, não constatados o falseamento de identidade ou o anonimato e vedada a adoção de interpretação extensiva para incidência de multa, é inviável o deferimento do pedido de aplicação de sanção aos responsáveis pela divulgação do conteúdo alegado inverídico e ofensivo. Ademais, a Res.-TSE no 23.551/2017, em seu S $0^{\circ}$ do art. 23, afasta a responsabilidade das pessoas naturais que, espontaneamente, se manifestarem na Internet em matéria político-eleitoral - sob a forma de elogio ou crítica a candidato ou partido político - por meio de blogs, redes sociais, sítios de mensagens instantâneas e aplicações de Internet assemelhadas cujo conteúdo seja gerado ou editado. Da mesma forma, no tocante às representadas Facebook Serviços Online Brasil Ltda., Google Brasil Internet Ltda. e Twitter Brasil Rede de Informações Ltda., também não deve incidir a sanção prevista na legislação eleitoral, pois não houve descumprimento de decisão judicial que autorize a aplicação da reprimenda. Do exposto, em relação ao representante extingo a representação Luiz Inácio Lula da Silva, ante sua ilegitimidade ativa. Quanto ao pedido de direito de resposta, julgo prejudicada a ação, pela perda superveniente de seu objeto, e improcedente o pedido de aplicação de multa aos responsáveis pelas publicações, restando, por fim, sem efeito a medida liminar concedida nestes autos, consoante preconiza o art. 33 \ $6^{\circ}$ da Res.-TSE no 23.551/2017."
} 
de, mostra-se contraproducente ingressar na Justiça Comum para conseguir nova liminar sobre a mesma questão.

Apesar disso, no que diz respeito à aplicabilidade do art. 33 parágrafo $6^{\circ}$ da Resolução n. 23.551 do TSE, o Ministro Relator do caso, Admar Gonzaga, manteve o entendimento da decisão recorrida pela perda da eficácia da liminar anteriormente concedida, votando pelo desprovimento do recurso interposto.

Em vista, o Ministro Edson Fachin seguiu o Relator no sentido de extinguir os efeitos da liminar, porém, manifestou apoio à continuação do debate durante a elaboração das resoluções futuras, de modo a expandir o amparo ao candidato, aos eleitores e ao processo político como um todo. Conforme suas palavras "A proteção que se dá ao candidato pode, na medida em que também protege o cidadão, projetar os seus efeitos mesmo que depois de findo o processo eleitoral”.

Ao final, por maioria dos votos, negou-se provimento ao recurso, mantendo a revogação da medida liminar anteriormente deferida, nos termos do art. $33 \int 6^{\circ}$ da Resolução n. 23.551/2017, do TSE ${ }^{15}$.

Essa decisão também aparece refletida em acórdão proferido nos autos de outra representação eleitoral que tramitou na Corte Superior e que tinha como objeto a mesma discussão. Nesse caso, restou consignado que:

(...) encerrado o período eleitoral, as ordens judiciais de remoção do conteúdo da internet proferidas por esta justiça especializada, independentemente da manutenção dos danos gerados pelas inverdades divulgadas, deixam de surtir efeito, devendo a parte interessada redirecionar o pedido, por meio de ação judicial autônoma, à Justiça Comum. (Autos n⿳⺈ 0601635-31.2018.6.00.0000).

O mencionado acórdão foi originado da representação eleitoral movida pela então candidata à vice-presidência, Manuela D’Ávila, também ajuizada em conjunto com a Coligação "O povo feliz de novo", em face do Facebook. A lide contestou a veracidade de vídeos que envolviam a então candidata, razão pela qual foi pleiteada, em caráter de urgência, a remoção do material da rede social.

\footnotetext{
${ }^{15}$ Embora o inteiro teor do acórdão não esteja disponível, os debates e decisão podem ser acessados em: https://www.youtube.com/watch?v=WIuGbOlFem0
} 
Após o deferimento de duas ordens liminares que determinaram a remoção das mídias caracterizadoras de propaganda eleitoral negativa, o Facebook comprovou o cumprimento das obrigações impostas, com a indisponibilização dos conteúdos.

Nesse mesmo sentido, o Ministro Sérgio Banhos, quando já encerrado o período eleitoral, decidiu que restou prejudicado o pedido de direito de resposta e julgou improcedente o pedido de aplicação de multa aos responsáveis pela divulgação dos conteúdos, entendendo que não houve comprovação do anonimato, sendo também revogados os efeitos das medidas liminares anteriormente deferidas, com fundamento no art. $33 \int 6^{\circ}$ da Resolução n. 23.551/2017 $7^{16}$.

Interposto recurso pelos representantes defendendo a continuidade dos efeitos da medida liminar para que os conteúdos removidos conti-

16 "Ao apreciar o pedido de tutela de urgência, entendi, com base no art. 57-D, \ 3으, da Lei n 9.504/1997, viável a concessão da liminar, porquanto o conteúdo o questionado, por ser inverídico, mesmo em caráter pedagógico, demandava a atuação desta Justiça Eleitoral, uma vez que, por atingir negativamente a imagem da candidata Manuela D’Ávila, poderia interferir na disputa eleitoral. Contudo, ultimado o pleito eleitoral de 2018, não perdura interesse processual no julgamento da representação, em relação ao pedido de concessão de direito de resposta, por suposta ofensa veiculada na Internet durante a campanha eleitoral. No que diz respeito ao pedido de aplicação de multa, verifico que as representantes fundamentam a incidência da sanção na violação aos arts. 57-B, $\iint 2^{\circ}$ e $5^{\circ}$, e $57-\mathrm{D}$, caput e $\int 2^{\circ}$, da Lei no 9.504/1997, que vedam o falseamento de identidade e o anonimato dos usuários de aplicação de Internet. Entretanto, cumpre esclarecer que não houve comprovação do alegado. Também não há falar em anonimato no Facebook, porquanto os dados cadastrais e os registros de acesso permitem a identificação dos responsáveis pelo conteúdo questionado (IDs 519280 e 560255). A propósito, veja-se o que já assentado por esta Corte (...) Dessa feita, não constatados o falseamento de identidade ou o anonimato e vedada a adoção de interpretação extensiva para incidência de multa, é inviável o deferimento do pedido de aplicação de sanção aos responsáveis pela divulgação do conteúdo apontado como ofensivo. Ademais, a Res.-TSE no 23.551/2017, em seu \ $0^{\circ}$ do art. 23, afasta a responsabilidade das pessoas naturais que, espontaneamente, se manifestarem na Internet em matéria político-eleitoral - sob a forma de elogio ou crítica a candidato ou partido político - por meio de blogs, redes sociais, sítios de mensagens instantâneas e aplicações de Internet assemelhadas cujo conteúdo seja gerado ou editado. Da mesma forma, no tocante à representada Facebook, também não deve incidir a sanção prevista na legislação eleitoral, já que não houve descumprimento de decisão judicial que autorize a aplicação da reprimenda. Do exposto, quanto ao pedido de direito de resposta, julgo prejudicada a representação, ante a perda superveniente de seu objeto, e improcedente o pedido de aplicação de multa aos responsáveis pelas publicações, ficando, por fim, sem efeito a medida liminar concedida nestes autos, consoante preconiza o art. 33 \ 6을 da Res.-TSE no 23.551/2017.” 
nuassem indisponíveis definitivamente, o Relator, Ministro Tarcísio Vieira de Carvalho, se posicionou pelo desprovimento, o que foi confirmado por maioria dos votos no Tribunal.

De igual forma, o Ministro Alexandre de Moraes registrou sua divergência, ratificando que os conteúdos deveriam permanecer removidos depois de encerradas as eleições por força da ordem judicial emanada pela Justiça Eleitoral. O Ministro Fachin novamente mencionou que o tema merecia maior reflexão para as próximas resoluções.

Contando com esse panorama, conclui-se que a posição atual do Tribunal Superior Eleitoral é no sentido de que as ordens de remoção de conteúdo diante da propaganda eleitoral, seja ela negativa, seja antecipada, devem perder os efeitos após o encerramento do período eleitoral.

Como visto, após diversas discussões e apesar das divergências, o TSE optou por confirmar que as ordens proferidas pela Justiça Eleitoral deixarão de produzir efeitos após o encerramento do período eleitoral. Justifica-se tal entendimento em observância ao disposto na Resolução n.

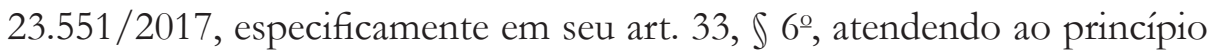
da menor interferência possível da Justiça Eleitoral no debate democrático.

Além disso, outro fundamento abordado é no sentido de que o encerramento do período eleitoral importa na finalização da proteção da honra do candidato, havendo o desaparecimento superveniente do interesse jurídico que lastreia a demanda.

Segundo o TSE, a tutela de honra dos cidadãos é matéria estranha à competência da Justiça Eleitoral especializada, e deve ser tutelada no âmbito da Justiça Comum. E, sendo assim, uma vez cassada a eficácia de uma decisão proferida pela Justiça Eleitoral, caso a ofensa persista, o prejudicado deverá pleitear o que entender de direito perante a Justiça Comum, inclusive de forma simultânea à eventual ação perante a Justiça Eleitoral, caso entenda conveniente.

Como afirmado pelo Tribunal Superior Eleitoral no julgamento das representações eleitorais mencionadas, a atividade da Justiça Eleitoral - no sentido de vedar o acesso de usuários a diversos tipos de conteúdos eventualmente publicados nas redes sociais - deve estar restrita ao período eleitoral, sendo certo que a Justiça Comum, tanto no âmbito Cível como no Criminal, tem plena capacidade de avaliar se um conteúdo, cujo ilícito 
foi verificado pela Justiça Eleitoral anteriormente, também seria ilícito na perspectiva generalista.

Outro ângulo sobre este debate reside na conexão indissociável do conteúdo e seu contexto. A aferição dos impactos do conteúdo depende, frequentemente, da análise de seu contexto. Em um contexto eleitoral e dependendo das peculiaridades que envolvam seus atores ou o cenário em que se desenvolve a campanha eleitoral, até eventuais elogios podem se transformar em ofensas.

Os requisitos avaliados pela Justiça Eleitoral para configuração de ilícitos são sempre específicos, ou seja, determinado conteúdo pode ser considerado ilícito pela Justiça Eleitoral por afetar diretamente de forma negativa a disputa eleitoral em andamento, mas, de forma oposta, pode não ser considerado ilícito sob uma perspectiva da Justiça Comum, quando o período eleitoral não estiver mais em andamento.

O retorno do conteúdo não parece afrontar a competência da Justiça Eleitoral, pelo contrário, é justamente pela delimitação especial da matéria eleitoral que, após o fim do contexto eleitoral, a atuação da Justiça Eleitoral em restrição de conteúdo digital deve cessar e com ela, caberá à Justiça Comum analisar a matéria, caso seja provocada especificamente para isso.

E, caso a Justiça Comum também considere ilícito o conteúdo em pauta, tem-se que a parte prejudicada continuará a ter a proteção necessária nesse sentido. Afinal, compete à Justiça Comum zelar pela honra dos jurisdicionados, ao passo que à Justiça Eleitoral compete proteger apenas a honra do candidato, que perde tal característica junto com o encerramento do pleito.

A esse respeito, vale mencionar a citação do Ministro Luis Felipe Salomão feita pelo Ministro Sérgio Banhos na decisão liminar proferida nos autos da Representação Eleitoral n. 0601765-21.2018.6.00.0000, referida no presente parágrafo:

encontradas publicações que apresentam realmente teor ofensivo ou negativo, é forçoso reconhecer que exteriorizam o pensamento crítico dos usuários das plataformas de rede sociais ora impugnadas, de modo que a liberdade de expressão no campo político-eleitoral abrange não só manifestações, opiniões e ideias majoritárias, socialmente aceitas, elogiosas, concordantes ou neutras, mas também aquelas minoritárias, contrárias às crenças estabelecidas, discordan- 
tes, críticas e incômodas". É que "o controle sobre quais conteúdos ou nível das críticas veiculadas, se aceitáveis ou não, deve ser realizado pela própria sociedade civil, porquanto a atuação da Justiça Eleitoral no âmbito da Internet e redes sociais, ainda que envolva a honra e reputação dos políticos e candidatos, deve ser minimalista, sob pena de silenciar o discurso dos cidadãos comuns no debate democrático".

Tendo em jogo, portanto, princípios constitucionais democráticos indispensáveis, tais como a vedação à censura, liberdade de expressão e manifestação de pensamento, bem como o acesso à informação, o art. 33 \$ 6ํㅡㄹ Resolução n. 23.551/2017 do TSE se mostrou como ponto de partida fundamental para que a atividade da Justiça Eleitoral exerça seu papel em proteção ao bom andamento do pleito, sem ultrapassar os limites estabelecidos pelos direitos fundamentais supracitados.

\section{A nova Resolução n. 23.610/2019 do TSE e o aprimoramento no escopo dos efeitos da decisão que determina a remoção de conteúdo ilícito eleitoral}

Apesar de o Tribunal Superior Eleitoral ter definido a posição discorrida acima acerca do objeto em discussão, ao que tudo indica, o debate sobre a perda de eficácia das ordens de remoção após o período eleitoral continuará se desenvolvendo para os próximos pleitos.

Como visto no julgamento dos leading cases sobre o assunto no TSE durante o ano de 2018, os Ministros Alexandre de Moraes e Edson Fachin manifestaram certa divergência quanto à aplicabilidade do art. 33 \$ 6ํㅡㄹ da Resolução n. 23.551/2017 nos exatos termos de sua redação, sendo o instituto da coisa julgada ponto essencial para fundamentar tal contrariedade.

Embora o racional do mencionado artigo tenha o objetivo de limitar o poder fiscalizatório da Justiça Eleitoral ao pleito, impedindo que a interferência na liberdade de expressão ultrapasse esse período, seria temerário ignorar que a redação do artigo nada dispõe sobre as situações em que já tenha transitado em julgado no mérito e sem revogação, a decisão que impôs obrigação de remoção de determinando conteúdo na internet.

Portanto, os termos do art. $33 \int 6^{\circ}$ da Resolução n. 23.551/2017 abrem margem, ainda que indiretamente, para que se discuta uma forma de superar a coisa julgada da decisão de mérito eleitoral. E, como é cediço, o 
art. 5, inciso XXXVI da Constituição Federal prevê que "a lei não prejudicará o direito adquirido, o ato jurídico perfeito e a coisa julgada".

Obviamente que se a redação do referido artigo fosse mantida nos termos em que foi inserida na Resolução n. 23.551/2017 do TSE, muitos questionamentos sobre sua constitucionalidade seriam levantados, gerando um risco à segurança jurídica, não apenas para a Justiça Eleitoral especializada, mas ao sistema legal como um todo.

Considerando esse contexto e particularidades, especificamente com relação ao pleito de 2020, já houve avanços, alterações e aprimoramento no entendimento anteriormente firmado pelo TSE frente ao disposto no art. $33 \int 0^{\circ}$ da Resolução n. 23.551/2017. O grupo de trabalho criado para a sistematização das normas eleitorais para as eleições do corrente ano, coordenado pelo próprio Tribunal Superior Eleitoral ${ }^{17}$, se manifestou no sentido de que:

(...) A ideia de se dar efemeridade sobre o resultado dos processos de remoção de conteúdo pode levantar o debate sobre violação à coisa julgada. É necessária a discussão acerca da melhor interpretação do texto da Resolução. (BASÍLIO et al., 2019).

Referido grupo de Sistematização das Normas Eleitorais foi capitaneado pelo Ministro Luiz Edson Fachin e teve como objetivo mapear inconsistências na legislação eleitoral vigente em 2018 e apontar soluções adequadas. O Eixo Temático III, coordenado pelo professor Alexandre Basílio Coura, foi responsável pela análise da legislação de regência da propaganda eleitoral e das pesquisas eleitorais, com vista à identificação de conflitos normativos, excessos ou falhas, e à propositura da respectiva sistematização.

Durante o projeto, foram analisados cerca de 30 diplomas normativos e 230 dispositivos, sendo levantadas em torno de 70 inconsistências, para as quais apresentaram-se as respectivas propostas de solução ${ }^{18}$.

\footnotetext{
${ }^{17}$ BASÍLIO, Alexandre et al. Diálogos para a construção da sistematização das normas eleitorais: Grupo II : Propaganda Eleitoral, Poder de Polícia, Direito de Resposta e Representações. Brasília: Tribunal Superior Eleitoral, 2019. Disponível em: <http://www.tse.jus.br/ legislacao/sne/arquivos/gt-iii-propaganda-estudos-preliminares>. Acesso em: 07 ago. 2019. ${ }^{18}$ Brasil. Tribunal Superior Eleitoral. Sistematização das normas eleitorais [recurso eletrônico]: eixo temático III: propaganda eleitoral e temas correlatos / Tribunal Superior Eleitoral. - Brasília: Tribunal Superior Eleitoral, 2019.
} 
No referido grupo de trabalho, quando analisados os artigos da Resolução n. 23.551/2017 para nova sistematização das normas que regeriam o próximo pleito de 2020 , foi indicado, quanto ao teor do art. 33, $\rrbracket 6^{\circ}$, a existência de inconsistência em relação ao art. $5^{\circ}$ inciso XXXVI da Constituição Federal, como esperado.

Para diagnosticar esse problema de incompatibilidade, foi avaliado que a própria redação do art. 33 \6º da Resolução n. 23.551/2017 levava à interpretação de que a coisa julgada seria "efêmera", quando se tratasse de conteúdo removido da internet, pois o artigo não tratava do possível cenário em que a decisão eleitoral que determinou a remoção do conteúdo já estivesse transitada em julgado no mérito sem revogação. Nesse sentido, o grupo de trabalho entendeu pela necessidade de implementação de mudanças no texto normativo do dispositivo, para promover melhor interpretação da resolução e evitar a possibilidade de eventual violação à coisa julgada ${ }^{19}$.

Assim, foi sugerida a seguinte alteração para a redação do dispositivo em voga na Resolução de 2019:

Findo o período eleitoral, as ordens judiciais de remoção de conteúdo da internet sem trânsito em julgado deixarão de produzir efeitos, cabendo à parte interessada requerer a remoção do conteúdo por meio de ação judicial autônoma perante a Justiça Comum.

Essa sugestão foi absorvida e lançada com pouquíssimas alterações na minuta da Resolução do TSE sobre propaganda eleitoral para as eleições do ano de 2020. Ocorre que, como pode ser percebido pelo teor da sugestão abaixo, essas alterações não afetaram o racional pretendido pelo grupo de sistematização das normas eleitorais:

Art. $38 \int 7^{\circ}$ : Realizada a eleição, as ordens judiciais de remoção de conteúdo da internet não confirmadas por decisão de mérito transitada em julgado deixarão de produzir efeitos, cabendo à parte interessada requerer a remoção do conteúdo por meio de ação judicial autônoma perante a Justiça Comum.

\footnotetext{
${ }^{19}$ Brasil. Tribunal Superior Eleitoral. Sistematização das normas eleitorais [recurso eletrônico]: eixo temático III: propaganda eleitoral e temas correlatos / Tribunal Superior Eleitoral. - Brasília: Tribunal Superior Eleitoral, 2019 - p. 83.
} 
Como é cediço, após a divulgação das minutas das resoluções que regulamentam as eleições de determinado ano, o TSE promove audiências públicas para discuti-las ${ }^{20}$. O objetivo é "receber contribuições de representantes de partidos políticos, de instituições públicas e privadas, de advogados que atuam na área eleitoral e da sociedade em geral com o objetivo de aperfeiçoar as minutas de resoluções relativas às eleições" ${ }^{21}$.

Entretanto, os demais players do processo eleitoral não apresentaram resistência à sugestão defendida pelo grupo de trabalho acerca da redação sugerida ao art. 38 \ $7^{\circ}$ da nova Resolução. Nessas condições, a redação do mencionado artigo se manteve tal como lançada na minuta e segue vigente na Resolução n. 23.610/19 (art. 38 ( $7^{\circ}$ ) para a corrida eleitoral de 2020.

Apesar disso, percebe-se que o entendimento do TSE foi alterado com o lapso temporal de apenas uma eleição, o que demonstra a dinâmica e velocidade que evolui a legislação eleitoral quando comparada com as demais normas positivadas pelo direito. Isso demonstra que a legislação eleitoral é mais flexível e capaz de acompanhar simultaneamente os anseios sociais que necessita atender.

De outra parte, o racional aplicado para tal alteração pontual na redação do artigo em discussão, que regulamenta a eficácia da decisão que determina a retirada de conteúdo na internet, apenas aperfeiçoa o dispositivo para que não haja prejuízo a outro instituto do direito garantido constitucionalmente, qual seja, a coisa julgada. Tal mudança, consequentemente, garante maior segurança jurídica à Justiça Eleitoral especializada, mas não afeta a pretensão de que a atividade fiscalizatória da Justiça Eleitoral seja limitada ao pleito, deixando apenas claro que, para eventual conteúdo ser reativado, a ordem de remoção deverá ser revogada antes de seu trânsito em julgado no mérito.

\footnotetext{
${ }^{20}$ As audiências públicas relacionadas às resoluções das eleições são obrigatórias e ocorrem no segundo semestre do ano anterior ao pleito. A obrigatoriedade das audiências é fixada pelo art. 105 da Lei n 9.504/1997. Disponível em:< https://www.tse.jus.br/imprensa/noticias-tse/2019/Novembro/tse-realizara-audiencias-publicas-sobre-as-resolucoes-das-eleicoes-e-das-financas-e-contabilidade-dos-partidos-politicos>. Acesso em: 14 out. 2020.

${ }^{21}$ Disponível em:< https://www.tse.jus.br/imprensa/noticias-tse/2019/Novembro/tse-realizara-audiencias-publicas-sobre-as-resolucoes-das-eleicoes-e-das-financas-e-contabilidade-dos-partidos-politicos >. Acesso em: 14 out. 2020.
} 


\section{Considerações finais}

Este artigo teve como missão explorar a perda da eficácia das decisões judiciais que determinam a remoção de conteúdo na internet durante o processo eleitoral. Para isso, foram analisados casos concretos, como a Representação Eleitoral de no 0601765-21.2018.6.00.0000, embasados na Resolução n. 23.551/2017, que disciplinou a matéria durante o pleito de 2018. Assim, foi possível perceber uma inclinação do Tribunal Superior Eleitoral em garantir que a competência da Justiça Eleitoral não ultrapasse as suas atribuições e invada o espaço íntimo e comum do cidadão fora do período das eleições.

Foi feita análise cautelosa do disposto no art. 33 parágrafo $6^{\circ}$ da referida resolução mediante construção do panorama fiscalizatório da Justiça Eleitoral, passando pelo fenômeno da modernização da forma de fazer propaganda e a instituição de novas tecnologias no processo. Temas como censura, liberdade de expressão, acesso à informação e à proteção a outros direitos fundamentais foram explorados a partir de uma perspectiva normativa frente à aplicabilidade do referido art. 33.

Os pontos levantados pelo grupo de trabalho trouxeram luz ao tema e deram pistas a respeito de como seriam elaboradas as resoluções para 2020. De fato, os debates sobre o tema de retirada de conteúdo e da perda de eficácia das decisões foi posto frente a uma lente mais recente, quando analisamos mais a fundo a nova Resolução n. 23.610/2019 que disciplina as eleições de 2020.

As mudanças em conceitualização desses conceitos e do ponto de partida da volta do conteúdo indicam que a forma de aplicar o assunto ainda não se consolidou. Assim, entende-se ser necessário mais um ciclo eleitoral para definir com mais clareza a inclinação definitiva do TSE a respeito da reativação do conteúdo eleitoral irregular removido da internet após o encerramento do pleito.

Conclui-se, portanto, que, como perspectivas para o futuro, a constante consolidação dos entendimentos sobre a perda do objeto deverá acompanhar o resultado de outros estudos e discussões, visto que as alterações nas resoluções de 2017 e 2019 não permitem estabelecer, ainda, total certeza jurídica sobre o tema. Como o assunto é recente e, portanto, longe de estar consolidado, somente com a publicação das novas resoluções para as próximas eleições é que será possível confirmar o destino da disposição 
do art. $33 \int 6^{\circ}$ da Resolução n. 23.551/2017 e do art. 38 \ 7ํ da Resolução n. 23.610/2019 do TSE, assim como suas aplicabilidades para o futuro.

\section{Referências}

COURA, Alexandre et al. Diálogos para a construção da sistematização das normas eleitorais: Grupo II : Propaganda Eleitoral, Poder de Polícia, Direito de Resposta e Representações. Brasília: Tribunal Superior Eleitoral, 2019. Disponível em: < http://www.tse.jus.br/legislacao/sne/arquivos/gt-iii-propaganda-estudos-preliminares>. Acesso em: 07 ago. 2019.

BRAGA, Sérgio; CARLOMAGNO, Márcio Cunha. Eleições como de costume? Uma análise longitudinal das mudanças provocadas nas campanhas eleitorais brasileiras pelas tecnologias digitais (1998-2016). Revista Brasileira de Ciência Política, Brasília, n. 26, p. 7-62, maio/ago. 2018.

BRASIL. Tribunal Superior Eleitoral. Sistematização das normas eleitorais (recurso eletrônico): eixo temático III: propaganda eleitoral e temas correlatos. Brasília : Tribunal Superior Eleitoral, 2019. 97 p. (Coleção SNE, 4) FUNDO amplia em 25 vezes dinheiro público a partidos políticos. O Estado de S. Paulo, São Paulo, 21 jul. 2019. Disponível em:<https://politica.estadao.com.br/noticias/geral,fundo-amplia-em-25-vezes-dinheiro-publico-a-partidos-politicos,70002930509>. Acesso em: 23 jul. 2019.

GOLDZWEIG, Rafael. Por que devemos nos preocupar com a influência das redes sociais nas eleições 2018? Disponível em: < https://brasil. elpais.com/brasil/2018/09/21/opinion/1537557693_143615.html>. Acesso em: 23 jul. 2019.

IBOPE, Inteligência. Redes sociais e mídias tradicionais são as fontes de informação com mais influência na escolha do presidente em 2018. Disponível em: <http://www.ibopeinteligencia.com/noticias-e-pesquisas/ redes-sociais-e-midias-tradicionais-sao-as-fontes-de-informacao-com-mais-influencia-na-escolha-do-presidente-em-2018/> . Acesso em: 23 jul. 2019.

RAIS, Diogo; FALCÃO, Daniel; MENEGUETTI, Pamela; GIAC-CHETA, André. Direito Eleitoral Digital. São Paulo: Revista dos Tribunais, 2018.

RODEGHERI, Letícia Bodanese. (2013). Liberdade de expressão na web: análise de decisões judiciais sobre a remoção de conteúdo em sites. Revista Espaço Acadêmico, 13 (151), 54-62. 
TEIXEIRA, Viviani Corrêa. Competição Eleitoral no Cenário Brasileiro Utilizando a Internet: Ágora ou Clientela. Esferas, [s.l.], v. 1, n. 12, p.9-18, 8 nov. 2018. Universidade Católica de Brasília. DOI: http://dx.doi. org/10.31501/esf.v1i12.8267.

Alinne Lopes Gomes - Advogada na Diogo Rais Consultoria Jurídica. Diretora de Comunicação e Pesquisadora do Instituto Liberdade Digital. Graduada em Direito pela Universidade Presbiteriana Mackenzie com bolsa pesquisa em direito eleitoral digital pelo grupo MackEleições, coordenado pelo professor Diogo Rais. Autora da pesquisa "LGBT policies and overall safety in Brazil” em conjunto com a ONG Safety First For Girls. E-mail: alinne. lopes@diogorais.com.br.

Diogo Rais - Mestre e Doutor em Direito do Estado pela Pontifícia Universidade Católica de São Paulo. Professor de Direito Eleitoral da Universidade Presbiteriana Mackenzie. Colunista do Valor Econômico nas eleições de 2016 e da Folha de S. Paulo nas eleições de 2018. Coordenador dos livros "Direito Eleitoral Digital" e "Fake News: a conexão entre a desinformação e o Direito", ambos publicados pela Revista dos Tribunais, em 2018. E-mail: professordiogorais@gmail.com.

Frederico W. P. Pol Fernandes - Advogado nas áreas de contencioso civil e eleitoral, especializado em direito digital e do consumidor de TozziniFreire Advogados. Graduado em Direito pela Universidade Presbiteriana Mackenzie. Pós-graduando em Propriedade Intelectual e Novas Tecnologias pela FGV-SP. E-mail: ffernandes@tozzinifreire.com.br.

Patrícia Helena Marta Martins - Sócia de TozziniFreire Advogados nas áreas de contencioso civil e eleitoral, especializado em direito digital e do consumidor de TozziniFreire Advogados. E-mail: pmarta@tozzinifreire.com.br. 